\title{
Türkiye'de Para İkamesine Karşı Politika Faizi Etkin Olarak Kullanılıyor Mu? Fourier Alandan Kanitlar
}

Tayfur BAYAT (https://orcid.org/0000-0002-4427-0999), İnönü University, Turkey; tayfur.bayat@inonu.edu.tr Şebnem TAŞ (https://orcid.org/0000-0002-7303-3407), Firat University, Turkey; stas@firat.edu.tr

\section{Is Policy Interest Effectively Used in Turkey for Against Currency Substitution: Evidence from Fourier Area}

\begin{abstract}
The phenomenon of currency substitution started in the Turkish economy during the transition to a free-market economy in the 1980s with the changing foreign exchange regime. In this context, the study, based on the January 2011-November 2020 period, Turkey's economy to prevent currency substitution, whether the weighted average funding rate is used effectively or not, is examined by traditional and Fourier causality tests. As a result of empirical analysis, it has been determined that currency substitution hysteria is experienced due to economic actors' deterioration in nominal exchange rate expectations. To rectify this situation, no interest rate hysteresis was experienced during the analysis period due to the inability to use the policy rate effectively. As the study's main question, both time and Fourier domain causality from average funding cost to money substitution could not be found.
\end{abstract}

Keywords : $\quad \begin{aligned} & \text { Currency Substitution, Policy Interest, Fourier Approximation, } \\ & \text { Causality. }\end{aligned}$

JEL Classification Codes : C22, E43, E52, F31.

$$
\text { Öz }
$$

Para ikamesi olgusu Türkiye ekonomisinde, 1980'li yıllarda serbest piyasa ekonomisine geçiş ve kambiyo rejiminde yapılan değişiklik ile yer bulmaya başlamıştır. Bu kapsamda çalışmada, Türkiye ekonomisinde Ocak 2011-Kasım 2020 dönemi baz alınarak para ikamesinin engellenmesi amacıyla ağırlıklı ortalama fonlama faizinin etkin olarak kullanılıp kullanılmadığı geleneksel ve Fourier nedensellik testleri ile incelenmektedir. Ampirik analizler sonucunda ekonomik aktörlerin nominal döviz kuru beklentilerinde bozulma nedeniyle para ikamesi histerisinin yaşandığ tespit edilmiştir. Bu durumun düzeltilmesi amacıyla politika faizinin etkin olarak kullanılamaması nedeniyle analiz periyodunda faiz oranı histerisi yaşanmamıştır. Çalışmanın temel sorusu olarak ağırlıklı ortalama fonlama maliyetinden para ikamesine doğru hem zaman hem de Fourier alanda nedensellik bulunamamıştır.

Anahtar Sözcükler $\quad$ : $\quad$ Para İkamesi, Politika Faizi, Fourier Yaklaşım, Nedensellik Testleri. 
Bayat, T. \& Ş. Taş (2021), "Türkiye'de Para İkamesine Karşı Politika Faizi Etkin

Olarak Kullanılıyor Mu? Fourier Alandan Kanıtlar”, Sosyoekonomi, 29(50), 503-520.

\section{Giriş}

Küreselleşmenin en önemli etkilerinden biri olan finansal liberalizasyonla birlikte ülkeler arasındaki sınırlar kalkmış, bağlantılar güçlenmiş ve bu da ülkelerin ticari faaliyetlerinin artmasına neden olmuştur. Bu ticari faaliyetler, ülke para birimlerinin konvertibl olmasıyla beraber hızlanmıştır. Türkiye'nin özellikle 1980'li yıllardan sonra serbest piyasa ekonomisine geçişi ve 1989 yılında ülke para biriminin konvertibl hale gelmesiyle uluslararası pazara girişini kolaylaştırarak ticaret hacminin artmasına yol açmıştır. Sürecin işleyişine bağlı olarak finansal serbestleşme, avantajlarının yanında kırılgan bir yapının oluşmasına da neden olmuştur. Bu kapsamda Türkiye'de 1980 öncesi dönemde, ekonomik birimlerin döviz bulundurması ve kullanması yasak olduğundan para ikamesi sorunu da yaşanmamaktaydı. Ancak 24 Ocak 1980 kararları sonrasında kambiyo rejiminde yapılan değişiklikler ile beraber yabancı para birimleri ile ilgili bahsedilen kısıtlamalar ortadan kaldırılmış ve çeşitli güdüler nedeni ile talep edilir ve kullanılır hale gelmiştir (Balaylar \& Duygulu, 2004: 33).

Yaşanan bu sürecin ardından para ikamesi olgusu ülke ekonomisinde önemli bir yer tutmaya başlamıştır. Küresel açıdan bakıldığında ise, özellikle 1997 yılında yaşanan Asya mali krizi ve ülkelerin finansal sistemlerinin zayıf olmasından kaynaklı olarak yaratmış olduğu domino etkisiyle birçok ülkenin olumsuz anlamda etkilenmesi, para ikamesi için önemli bir örneği oluşturmaktadır. Özellikle böyle dönemlerde ülkelerin yaşamış olduğu ekonomik sorunlardan dolayı bireylerin değer kaybeden ulusal paradan kaçışı ve daha güçlü olan yabancı para birimine geçişi söz konusu olabilmektedir. Bu kapsamda 1980'lerin ikinci yarısında birçok Avrupa ülkesinde finansal liberalizasyonla birlikte elde yabancı para tutma konusunda hızlı bir artış olduğu görülmektedir (Giovanni \& Turtelboom, 1982). Türkiye’de ve gelişmekte olan ülkelerin birçoğunda yaşanan enflasyon sorunu, faiz oranları makroekonomik sorunlar, ulusal paranın değer kaybı vb. faktörlerden kaynaklı olarak para ikamesinin arttığı görülmektedir. Bu motivasyondan hareketle, bu çalışmada Türkiye'de para ikamesi ile faiz oranları arasındaki ilişki araştırılmaktadır. Kwiatowski vd. (1992, KPSS) tarafından geliştirilen doğrusal birim kök testi ile Becker vd. (2006) tarafından geliştirilen Fourier birim kök testi ile para ikamesi ve faiz oranı histerisinin varlığı test edilmektedir. Ayrıca para ikamesi ve faiz oranları arasındaki nedensellik ilişkisi Granger (1969), Toda ve Yamomoto (1995), Enders ve Jones (2016), Nazlioglu vd. (2016) tarafindan geliştirilen geleneksel ve Fourier nedensellik testleri ile incelenmektedir.

Literatürde Türkiye özelinde yer alan çalışmalara bakıldığında, para ikamesi ve faiz oranları arasındaki ilişkinin genellikle geleneksel nedensellik testleri ile analiz edilmeye çalışıldığı, Fourier nedensellik testlerinin kullanılmadığı görülmektedir. Bu kapsamda çalışmamızda söz konusu değişkenler arasındaki ilişkinin tespiti amacıyla geleneksel nedensellik testlerinin yanı sıra Fourier nedensellik testlerinin de kullanılması, çalışmayı önemli kılmakta ve literatürdeki boşluğu gidermeye katkıda bulunmaktadır.

Çalışmanın devam eden kısmında ilk olarak değişkenlere ait teorik altyapı ve literatürde yer alan çalışmalar üzerinde durulacak, ardından ampirik analiz yöntemleri ile 
Bayat, T. \& Ş. Taş (2021), “Türkiye'de Para İkamesine Karşı Politika Faizi Etkin

Olarak Kullanıliyor Mu? Fourier Alandan Kantllar”, Sosyoekonomi, 29(50), 503-520.

elde edilen bulgular analiz edilecek ve en son bölümde sonuç ve politika önerilerine yer verilecektir.

\section{Teorik Altyapı ve Literatür}

Paranın değer saklama, işlem amaçlı ve hesap birimi olma fonksiyonlarından, değer saklama niteliğini yitirmesi sonucu değişim aracı olarak farklı para birimlerinin ulusal para yerine kullanımı literatürde para ikamesi olarak ifade edilmektedir (Cuddington, 1989). Yabancı paranın ulusal para yerine hesap birimi, değişim ve değer saklama aracı olarak kullanılması ise "dolarizasyon olarak ifade edilmektedir (Calvo \& Végh, 1992). Yapılan çalışmaların birçoğunda dolaşımda olan yabancı para hakkında genellikle veri olmadığından dolayı bu çalışmada da kullanıldığı üzere para ikamesi göstergesi olarak döviz mevduatlarının M2 para arzına oranı olarak ifade edilen dolarizasyon oranı kullanılmaktadır (Savastano, 1992). Para ikamesi kavramının belirleyicileri ve para ikamesi konusunda geniş bir literatür mevcuttur. İlk çalışmalar Bretton Woods sisteminin terk edilmesiyle ulusal paraların yabancı para birimleri karşısındaki aşırı dalgalanmaların bir açıklaması olarak yapılmıştır (Civcir, 2005). Meksika ekonomisi üzerine yapılan çalışmada Ortiz (1983) para ikamesinin temel belirleyicilerinin devalüasyon beklentisi ve kur riskiyle ilgili faktörlerden kaynaklandığı sonucuna ulaşmıştır.

Devalüasyon konusunda bireylerin hareketlerinin para ikamesini artırıp artırmayacağı algılama biçimiyle ilgilidir. Devalüasyon sonucunda bireyler bunu servet artışı olarak algılar ise ulusal para talebi artacak yani para ikamesi azalacaktır. Diğer taraftan yapılan devalüasyon daha fazla bir devalüasyon beklentisi oluşturursa ulusal paradan kaçış yabancı paraya geçiş hızlanacak yani para ikamesi artacaktır. Ayrıca para ikamesinin yaygın olduğu bir ülkede faiz oranındaki (hem reel hem de nominal) değişiklikler, para talebinin istikrarsızlığı nedeniyle belirsiz olacaktır (Adom vd., 2009). Bir diğer bulguya göre açık ekonomilerde hükümet politikalarından kaynaklanan enflasyonist ortamda bireylerin enflasyon vergisinden kaçma arzularının da para ikamesini artırdığ 1 ortaya konulmuştur (Canto \& Nickelsburg, 1987). Enflasyonun yüksek olduğu ülkelerde ulusal para değer saklama işlevini yitirecek ve enflasyona bağlı olarak ulusal paralara olan talep istikrarsız bir görünüm sergileyecektir (McKinnon, 1982). Para ikamesinin, refahı artırdığı (Sturzenegger, 1997), fakat para ikamesinin refah artırıcı olması için enflasyon oranının oldukça yüksek olması gerektiğine (Özbilgin, 2012) yönelik bulgular mevcuttur. Bunun tam tersi durumda para ikamesinin özel tüketimi dolayısıyla refahı azalttığı (Ghobaee Arani vd., 2018) da ifade edilmektedir.

Para ikamesinin refah azaltıcı etkileri, vergi kaçakçılığının maliyetlerinde azalmaya yol açma, 'kayıt dışı' ekonomiye katılımı kolaylaştırma, finansal işlemleri gizleyerek, işletme hırsızlığının maliyetini düşürme, yolsuzluk ve rant arayışını kolaylaştırma şeklindedir (Feige, 2003). Makroekonomik dengeyi olumsuz yönde etkileyen bu faktörlerin yanında para ikamesi ise döviz kurunda beklenenden çok daha büyük dalgalanma ve istikrarsızlara neden olmakta (Girton \& Roper, 1981) bu da ekonominin beklentilerden uzaklaşıp, kötüleşmesine yol açmaktadır. Para ikamesi ve faiz oranları arasındaki ilişki konusunda ise 
teorik altyapı para ikamesinin nedenlerinden olan enflasyonun önüne geçebilmek adına faiz oranlarının artırılmasını öngörmektedir. Literatürde Taylor kuralı adı verilen bu kavram enflasyon oranından daha yüksek bir faiz oranının belirlenmesi gerektiğini savunmaktadır. Para ikamesinin yurt içi faiz oranlarını etkilediğine dair ilk çalışma gelişmekte olan ülkeleri inceleyen Edwards ve Khan (1985) tarafindan yapılan çalışma olarak kabul edilmektedir. Düşük faiz ortamında enflasyondan korunmak için para ikamesinde artış söz konusu iken bunun tersi durumda yani enflasyon oranından daha yüksek bir faiz oranı sunulursa bireyler/yatırımcılar yabancı parayı tercih etmek yerine faiz oranlarında paralarını değerlendirmeyi tercih edebilir mi? sorusu önem kazanmaktadır.

Literatürde Türkiye üzerine yapılan bazı çalışmalar para ikamesi ile faiz oranı arasında negatif (Civcir, 2005), enflasyon ile arasında ise pozitif yönlü ilişki olduğu yönünde bulgular mevcuttur (Domac \& Oskooee, 2002). Para ikamesinin belirleyicileri konusunda yapılan çalışmalar, ulusal paranın değer kaybı /döviz kuru (Selçuk, 1994; Viseth, 2002; Yasuda, 2009; Pepic vd., 2015; Aigheyisi, 2015) ve faiz oranı (Clements \& Schwartz, 1993; Tkalec, 2013; Kumamoto, 2014; Manjani, 2015), siyasi şiddet (Fielding \& Shortland, 2012), siyasi belirsizliklerin (Doguwa, 2014) para ikamesini etkilediğini ortaya koymuşlardır. Para ikamesine neden olan faktörlerin yanı sıra Türkiye üzerine yapılan çalışmada para ikamesinin de döviz kuru oynaklığını artırdığına yönelik bulgular mevcuttur (Akçay, vd., 1997). Bir diğer bulguya göre para ikamesine neden olan faktörler ağ dışsallıkları (Oomes, 2003) ve devalüasyon olduğu fakat ağ dışsallıklarının devalüasyondan daha fazla para ikamesi üzerinde etkisi olduğudur (Valev, 2010). Bunlarla birlikte para politikasının pozitif ve negatif şoklarının para ikamesi üzerinde etkili olduğu ancak pozitif para politikası şoklarının para ikamesi üzerinde daha baskın olduğu (Sökmen, 2021), Türkiye'de para ikamesinin ekonomik birimlerin spekülatif ticaretleri nedeni ile gerçekleşmediği, siyasi olayların ekonomik olaylara kıyasla para ikamesi üzerinde daha güçlü bir etkiye sahip olduğu (Mişu vd., 2020), hem uzun hem de kısa dönemde enflasyon, döviz kuru değer kaybı ve finansal derinleşmenin para ikamesi için önemli bir belirleyici olduğu (Tarawalie \& Jalloh, 2020) ve hükümetlerin para ikamesinin yüksek olduğu durumlarda likidite zorluklarını hafifletmek için doğrudan yabancı yatırım girişlerini teşvik eden ortamı yaratması gerektiği ve bunun için de faiz oranlarının önemli bir araç olduğuna dair ampirik sonuçlar bulunmaktadır (Tomu vd., 2021).

Kısaca özetlemek gerekirse para ikamesinin nedenlerinin başında yüksek enflasyon (Bernholz, 1989; Drazen \& Helpman, 1990; Imrohoroğlu, 1994; Babatope-Obasa \& Aziakpono, 2004) paranın değerini koruma arzusu, ithal mal alımı için kullanımı veya ülkede kontrolden çıkan enflasyonla başa çıkmak resmi olarak tamamen ulusal paranın yabancı bir parayla değişimi şeklinde sayılabilir. Burada sorun şu ki yaşanan yüksek enflasyon ve ekonomik istikrarsızlıklardan kaynaklanan para ikamesi bir süre sonra kalıcı hale gelerek eski seviyelere dönmeyebilir. İşte bireylerin kendi tasarruf yöntemlerini bulduğu ve paralarının değerlerini koruma adına uyguladıkları para ikamesi davranışının kalıcı hale gelme olayına "para ikamesi histerisi" denir (Savastano, 1996). Para ikamesi histerisi konusunda çeşitli modeller geliştirilmiştir (Guidotti \& Rodriguez, 1992; Uribe, 1997; Sturzenegger, 1997). Bu modeller satın alma gücü riski modeli ve ağ dışsallıkları 
Bayat, T. \& Ş. Taş (2021), “Türkiye'de Para İkamesine Karşı Politika Faizi Etkin

Olarak Kullanıliyor Mu? Fourier Alandan Kantllar”, Sosyoekonomi, 29(50), 503-520.

şeklindedir (Valev, 2010). Para ikamesi histerisi hakkındaki çalışmalar incelendiğinde histeri etkisinin varlığı (Samreth, 2011) ve bu etkinin giderilemeyeceği (Ghaderi, 2017) ifade edilmektedir. Bu görüşe karşıt bir görüş olarak para ikamesi histeri etkisinin sabit kur rejimine geçişle giderilebileceğine dair bulgular da mevcuttur (Shahin \& Freiha, 2005).

\section{Kapsam ve Veri Seti ve Ampirik Sonuçlar}

Bu çalışmada Ocak 2011-Kasım 2020 döneminde Türkiye'de para ikamesi ve faiz oranları arasındaki ilişki Türkiye Cumhuriyet Merkez Bankası ağırlıklı ortalama fonlama maliyeti (weighted average cost of the Central Bank of the Republic of Turkey, WACF) ile döviz tevdiat hesaplarının M2 para arzına oranı (CS) değişkenleri kullanılarak araştırılmaktadır. Türkiye Cumhuriyet Merkez Bankası'nın piyasalarda oluşan faizlere yön vermek amacıyla daha çok ağırlıklı ortalama fonlama maliyetini kullanması çalışmada bu değişkenin faiz oranı göstergesi olarak alınmasına neden olmuştur. T.C. Merkez Bankası ağırlıklı fonlama maliyetini gecelik borç verme faizinin ve haftalık repo faizinin ağırlıklı ortalamasını alarak oluşturmaktadır. Para ikamesi göstergesi olarak baz alınan döviz tevdiat hesapları/M2 oranında, döviz tevdiat hesapları, Türkiye'de yerleşik gerçek ve tüzel kişiler ile yurtdışında yerleşik gerçek ve tüzel kişilerin T.C. Merkez Bankası ve bankalar nezdinde tuttukları dövizlerden oluşmaktadır. Bu kapsamda döviz tevdiat hesaplarının M2 para arzına oranı ülkedeki para ikamesinin düzeyini net bir şekilde ortaya koymaktadır.

Çalışmanın ampirik bölümünde ilk olarak tanımlayıcı istatistikler ve daha sonra Kwiatowski vd. (1992, KPSS) tarafından geliştirilen doğrusal birim kök testi ile Becker vd. (2006) tarafından geliştirilen Fourier birim kök testi ile para ikamesi ve faiz oranı histerisinin varlığı incelenmektedir. Ardından Granger (1969), Toda ve Yamomoto (1995), Enders ve Jones (2016), Nazlioglu, vd. (2016) tarafından geliştirilen geleneksel ve Fourier nedensellik testleri ile para ikamesi ve faiz oranları arasındaki ilişki araştırılmaktadır.

Geleneksel birim kök testlerinde zaman serilerinin deterministik trendinde oluşan yapısal değişmelerinin göz önünde bulundurulmaması, serilerin birim kök test sonuçlarının farklı olmasına neden olabilmektedir. Bu durumun üstesinden gelebilmek amaciyla Kwitkowski vd. (1992)'ne ait KPSS birim kök testi, Becker vd. (2006) tarafindan yapısal değişimler dikkate alınarak genişletilmiş ve yapısal değişimler Fourier fonksiyonu kullanılarak dikkate alınmıştır. Bu sayede geleneksel testlerde yapısal kırılmaların sayısı ve yapısının önceden bilinmesinin zor olması durumu Fourier fonksiyonların kullanımı ile aşılmakta ve güçlü sonuçlar elde edilebilmektedir. Söz konusu bu özellikleri nedeni ile çalışmamızın ampirik analiz kısmında, geleneksel testlerinin yanı sıra Fourier nedensellik testleri de kullanılmaktadır. 
Grafik: 1

Faizlerin Ampirik Analiz Periyodu Boyunca Gelişimi

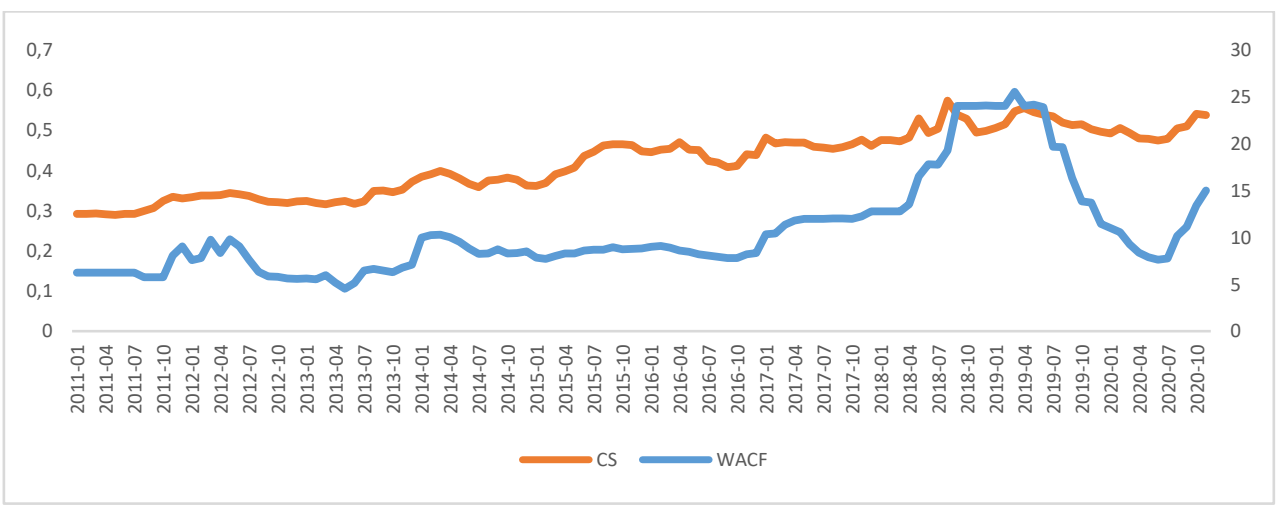

Grafikte sol eksen döviz tevdiat hesaplarının M2 para arzına oranını ve sağ eksen ise ağırlıklı ortalama fonlama maliyetini göstermektedir. Türkiye'nin 2011:1-2020:9 dönemine ait grafik değişkenler arasındaki ilişkiyi doğrusal ilişkiyi ifade etmektedir. Para ikamesinin Türkiye'de bazı dönemler dışında (2015:1, 2016:9,2018:9,2020:5) bir artış eğilimde olduğu yönündedir. Para ikamesinde azalmanın olduğu yılların neredeyse tamamında faiz oranların bir düşüş olduğu görülmektedir. Türkiye'de faizler ve para ikamesi arasındaki negatif ilişkiyi ifade eden ve Civcir (2005) çalışmasını destekleyen dönemin 2018:9-2019:5 arasında olduğu görülmektedir.

\section{Tablo: 1}

\section{Tanımlayıcı İstatistikler}

\begin{tabular}{|c|c|c|c|c|c|c|c|c|c|c|}
\hline & WACF & CS & $\begin{array}{c}\text { Aritmetik } \\
\text { Ortalama }\end{array}$ & Max. & Min. & $\begin{array}{c}\text { Std. } \\
\text { Sapma }\end{array}$ & $\begin{array}{c}\text { Varyasyon } \\
\text { Katsay1s1 }\end{array}$ & Çarpıklık & Basıllık & Jarque-Bera (prob.) \\
\hline WACF & 1 & - & 10.59 & 25.5 & 4.52 & 5.16 & 0.48 & 1.55 & 4.57 & $60.12(0.00)^{* * *}$ \\
\hline CS & 0.762 & 1 & 0.41 & 0.57 & 0.28 & 0.07 & 0.17 & -0.07 & 1.72 & $8.21(0.016)^{* *}$ \\
\hline
\end{tabular}

Not: ***, **ve $*$ değerleri strasılyla $\% 1 . \% 5$ ve \%10 anlam seviyelerinde alternatif hipotezin kabul edildiğini göstermektedir.

Ağırlıklı ortalama fonlama maliyeti ile döviz tevdiat hesaplarının M2 para arzına oranı arasında pozitif ve nispeten güçlü bir korelasyon bulunmaktadır. Ağırlıklı ortalama fonlama maliyeti en yüksek değerine Mart 2019 tarihinde, en düşük değerine ise Mayıs 2013 tarihinde ulaşmıştır. Para ikamesi oranı ise en yüksek değerine Ağustos 2018 ve en düşük değerine ise Mayıs 2011 tarihinde ulaşmıştır. Ağırlıklı ortalama fonlama maliyeti dolarizasyon rasyosundan daha öngörülemez bir yapıya sahiptir. Ağırlıklı ortalama fonlama maliyetinin dağılımı sağa çarpık ve dik olmasına rağmen döviz tevdiat hesaplarının M2 para arzına oranı sola çarpık ve basık bir dağılıma sahiptir. Her iki değişkende normal dağılıma sahip değildir. 
Zaman serileri analizinde sahte regresyon problemi ile karşılaşmamak amacıyla serilerin durağan olup olmadıkları birim kök testleri ile sınanmalıdır. Bu bağlamda çalışmada geleneksel birim kök testi olan Kwiatowski vd. (1992)'nin geliştirdiği doğrusal KPSS birim kök testi ve Becker vd. (2006) tarafından geliştirilen Fourier KPSS birim kök testi kullanılmaktadır. Kwiatowski vd. (1992) doğrusal KPSS birim kök testinde, bir serinin deterministik bir eğilim etrafında durağan olduğu şeklindeki boş hipotezin testi önerilmektedir. Seri, deterministik eğilim, rastgele yürüyüş ve durağan hatanın toplamıdır ve test, rastgele yürüyüşün sıfır varyansa sahip olduğu hipotezinin LM testi olarak ifade edilir. İstatistiğin asimptotik dağılımı, boş ve serinin farkının durağan olduğu, alternatif hipotez altında elde edilir. Bu kapsamda test aşağıda yer alan lineer regresyon modelinden hareket eder.

$$
y_{t}=r_{1}+\beta_{t}+\varepsilon_{t} t=1, \ldots \ldots, T
$$

ve birbirini takip eden aşamaların ardından Kwiatowski vd. (1992)'ne ait test istatistiği 2 no'lu denklemdeki gibi gösterilir.

$$
\mu=T^{-2} \sum_{t=1}^{T} \frac{S_{t}^{2}}{S^{2}(l)}
$$

$H o$ ve $H_{1}$ hipotezleri aşağıdaki gibi gösterilmekte olup,

$$
\begin{aligned}
& H_{0}: \vartheta_{u}^{2}=0 \\
& H_{1}: \vartheta_{u}^{2}>0
\end{aligned}
$$

$\vartheta_{u}^{2}=0$ hipotezinde $\vartheta_{u}^{2}$ 'nin pozitif olduğu yani birim köke sahip olduğu hipotezine karş1lık otonom parametrelerinin sabit olduğu öne sürülmektedir.

Geleneksel birim kök testlerinde zaman serilerinin deterministik trendinde oluşan yapısal değişmelerinin göz önünde bulundurulmaması, serilerin birim kök test sonuçlarının farklı olmasına neden olacaktır. Becker, vd., (2006)'ne göre yapısal kırılmayı içeren birim kök testlerinde, deterministik trendde meydana gelen değişmenin kukla değişkenle belirlenmesi sorun yaratmaktadır.

Bu bağlamda Kwitkowski vd. (1992), tarafından geliştirilen KPSS birim kök testi, Becker vd. (2006) tarafından yapısal değişimler dikkate alınarak genişletilmiştir. Söz konusu testte yapısal değişimler Fourier fonksiyonu kullanılarak dikkate alınmıştır. Bu sayede serideki değişimler etkin bir şekilde tahmin edilebilmektedir. Yapısal kırılmaların sayısı ve yapısının önceden bilinmesi durumunun zor olması durumu Fourier fonksiyonlarının kullanımı ile aşılmakta ve bu sayede güçlü sonuçlar elde edilebilmektedir (Fendoğlu ve Gökçe, 2019:24). Bu kapsamda Becker vd. (2006) tarafından geliştirilen Fourier birim kök test istatistiği aşağıdaki gibidir.

$$
\begin{aligned}
\tau_{t}(k) & =\frac{1}{T^{2}} \frac{\sum_{t=1}^{T} \tilde{S}_{t}(k)^{2}}{\widetilde{\sigma}^{2}} \\
\tilde{S}_{t}(k) & =\sum_{j=1}^{t} \tilde{e}_{j}
\end{aligned}
$$




$$
\tilde{\sigma}^{2}=\tilde{\gamma}_{0}+2 \sum w_{j} \tilde{\gamma}_{j}
$$

$\tilde{e}_{j}$ Fourier fonksiyonuna ait hata terimi, $\tilde{\gamma}_{j}$ kalıntıların j. Oto kovaryanslarıdır. Söz konusu fonksiyonun anlamlı olup olmadığı $\mathrm{F}$ test istatistiği ile sınanır. $\mathrm{K}$ frekansına sahip Fourier modeli için $\mathrm{F}$ test istatistiği aşă̆ıdaki gibidir:

$$
F_{i}=\frac{\left(K K T_{0}-K K T_{1}(k)\right) / 2}{K K T_{1}(k) /(T-q)}, i=\pi, \tau .
$$

$K K T_{1}(k)$ regresyon denklemine ait kalıntı kareleri toplamı, $K K T_{0}$ trigonometrik terimleri içermeyen modele ait kalıntı kareler toplamıdır. F testinin uygulanabilmesi için temel hipotezin kabul edilmiş olması gerekmektedir (Fendoğlu \& Gökçe, 2019: 25).

Tablo: 2

\section{Doğrusal ve Fourier KPSS Test Sonuçları}

\begin{tabular}{|c|c|c|c|c|c|c|}
\hline & & Frekans (k) & Min KKT & FKPSS & F İstatistiği & KPSS \\
\hline \multirow{2}{*}{ WACF } & Sabitli Model & 1 & 1542.86 & 0.096 & 60.49 & $0.702^{* *}$ \\
\cline { 2 - 7 } & Sabitli ve Trendli Model & 3 & 1229.92 & 0.079 & 26.71 \\
\hline \multirow{2}{*}{ CS } & Sabitli Model & 1 & 0.237 & $0.517 * * *$ & 120.83 \\
\cline { 2 - 7 } & Sabitli ve Trendli Model & 3 & 0.057 & $0.124 * *$ & $21.239^{* * *}$ \\
\hline
\end{tabular}

Notlar: FKPSS testinde \%1, \%5 ve \%10 anlam seviyesinde kritik değerler strastyla $k=1$ 'de sabitli model için 0.131 , 0.172 ve 0.269 , sabitli ve trendli model için 0.047, 0.054 ve 0.071 ve $k=3$ te sabitli model için 0.339, 0.448, 0.718 ve sabitli ve trendli model için 0.114, 0.142 ve 0.210'dur. KPSS testinde \%1, \%5 ve \%10 anlam seviyesinde kritik değerler surasıyla sabitli model için 0.739, 0.463 ve 0.347, sabitli ve trendli model için 0.216, 0.146 ve 0.119'dur. ***, **ve* değerleri strasıyla \%1. \%5 ve \%10 anlam seviyelerinde serilerin dură̆anlıklarını göstermektedir.

Hem Kwiatowski vd. (1992) tarafından geliştirilen birim kök testinde hem de Becker vd. (2006) tarafından geliştirilen Fourier KPSS testinde boş hipotez değişkenin birim kök taşımadığı ve histeri etkisinin geçerli olmadığı, alternatif hipotez ise değişkenin birim kök taşıdığı ve histeri etkisinin geçerli olduğu şeklindedir. Eğer F test istatistiği kritik değerden büyük ise alternatif hipotez kabul edilmektedir. Eğer F test istatistiği kritik değerden küçük ise sıfır hipotezi kabul edilmektedir. Tablo 2'de yer alan sonuçlara göre hem ağırlıklı ortalama fonlama maliyeti hem de para ikamesi oranı doğrusal KPSS testinde sabitli modelde birim kök taşımakta ve histeri etkisi geçerli olmaktadır. Ancak sabit terimli ve trendli modelde ise tam tersi birim kök taşımamakta ve histeri etkisi geçerli olmaktadır.

Fourier KPSS birim kök testinde ise ağırlıklı ortalama fonlama maliyeti hem sabitli hem de sabit terimli ve trendli modelde birim kök taşımamakta ve histeri etkisi yaşamamaktadır. Ancak para ikamesi oranı ise hem sabitli hem de sabit terimli ve trendli modelde birim kök taşımakta ve histeri etkisi yaşamaktadır. Birim kök testlerinden elde edilen bu sonuçlara ampirik analiz periyodu ekonomik aktörlerin nominal döviz kuru beklentilerinde bozulma yaşadığı için ve döviz tevdiat hesaplarının M2 para arzına oranı belirli bir eşik değerin üstünde olduğundan dolarizasyon azalmamaktadır. Öte yandan para politikasının önemli araçlarından biri olan politika faizinin belirli bir bant aralığında pozitif reel faiz vermesi nedeniyle faiz histerisi yaşanmamaktadır. 
Ekonomik birimlerin makroekonomik istikrarsızlıklardan korunma amaçlı olarak ulusal para birimi yerine yabancı para birimini tercih etmeleri şeklindeki tepkileri olarak tanımlanan para ikamesinin, ekonomik istikrarsızlıkların giderilmesine rağmen eski seviyesine dönmemesi para ikamesi histerisi olgusunu ortaya çıarmaktadır. Hem Kwiatowski vd. (1992) tarafindan geliştirilen birim kök testinin hem de Becker vd. (2006) tarafından geliştirilen Fourier KPSS testinin sonuçları bir arada değerlendirildiğinde ele alınan dönem itibari ile Türkiye'de para ikamesi histerisinin geçerli olduğu anlaşılmaktadır. Yani özellikle yüksek enflasyon nedeniyle ulusal paranın satın alma gücünün düşerek değer kaybettiği ve faiz oranlarındaki belirsizliklerin yoğun olduğu dönemler gibi istikrasız ortamlarda para ikamesinin arttığı ancak daha sonraki dönemlerde enflasyondaki düşüşe ve yerli varlıklarının getirisindeki artışa rağmen para ikamesi seviyesinin düşmediği ve para ikamesinin sürdüğü görülmektedir.

Literatürde elde edilen bu sonuçları destekleyen çalışmalara bakıldığında bu durumun farklı nedenleri olabileceği görülmektedir. Guidotti ve Rodriguez (1992) Latin Amerika ülkelerinde para ikamesini ele aldıkları çalışmalarında ekonomik birimlerin para ikamesine geçiş süreçlerinde para birimini değiştirmeleri nedeni ile sabit bir maliyetle karşılaştıklarını ve bu maliyetin bir enflasyon bandı oluşturduğunu ileri sürmüşlerdir. $\mathrm{Bu}$ bandın varlığının ise para ikamesi histerisini gösterdiği ve özellikle Bolivya ve Meksika örneklerinde görüldüğü üzere enflasyondaki geçici değişikliklerin ekonominin para ikamesi derecesinde kalıcı etkilere ve dolayısıyla para ikamesi histerisinin oluşmasına neden olduğunun altını çizmişlerdir. Freitas (2003) farklı enflasyon deneyimleri ve para ikamesi seviyesine sahip olan Bolivya, Türkiye (yüksek enflasyon deneyimli) ve Endonezya (düşük enflasyon deneyimli) ülkelerinde para ikamesinin farklı dönüşüm kalıpları sergileyip sergilemediğini incelemiştir. Ele alınan bu üç ülkedeki dolarizasyon (para ikamesi) histerezisinin varlığına dair kanıtlar sunarak, bu olgunun yüksek düzeyde dolarize olmuş ekonomilerle veya uzun süre yüksek enflasyon oranları yaşayan ekonomilerle sınırlı olduğu görüşüne karşıt bir görüş sunmuştur. Buna göre yerli ve yabancı para birimleri, ödeme aracı olarak mükemmel ikameler ise, döviz talebi, istikrarın sağlamasının ardından azalmayacaktır. Havrylyshyn ve Beddies (2003) ise, Eski Sovyetler Birliği ülkelerindeki para ikamesi olgusunu ele aldıkları çalışmalarında bu ülkelerde para ikamesi düzeyinin çok yüksek düzeyde olduğunun ve bu durumun histeri etkisinin varlı̆̆ından kaynaklandığının altını çizmişlerdir. Bu bağlamda yüksek para ikamesinin ve para ikamesi histerisinin varlığının yalnızca ataletsel güven eksikliğinden kaynaklanmadığı, özellikle finans piyasalarında portföy çeşitlendirmesi için çok az sayıda alternatif araçtan biri olarak dövizin hem nakit hem de mevduat biçiminde kullanıldığını belirtilmektedir. 
Grafik: 2

CS için Sabitli Model

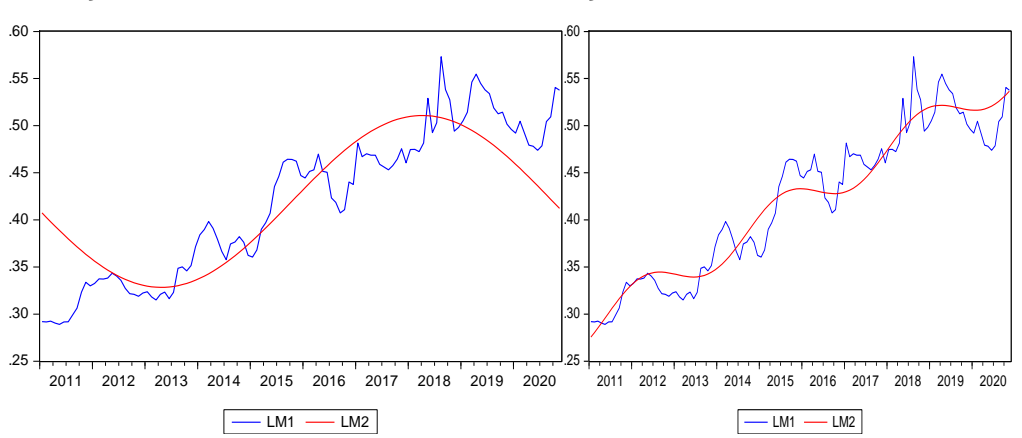

Grafik: 4

WACF için Sabitli Model

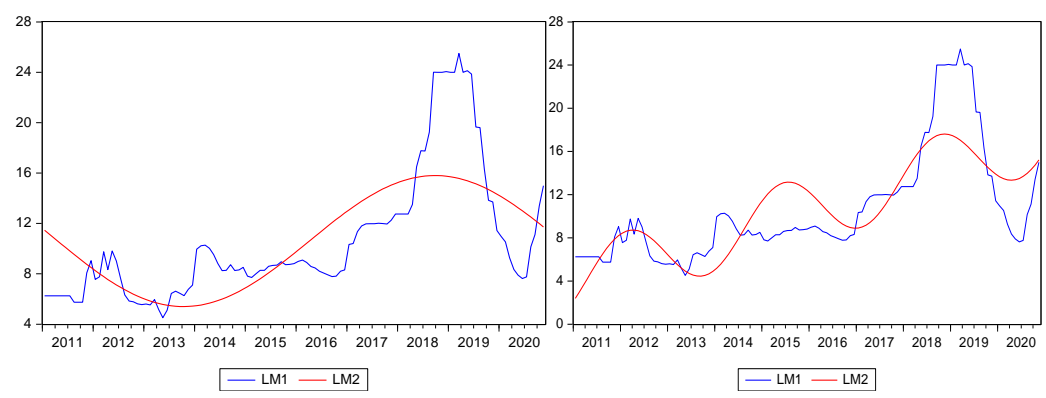

Yukarda yer alan grafiklerde LM1 değişkenlerin ham veri halini ve LM2 ise Fourier fonksiyonları ifade etmektedir. Hem para ikamesi oranının hem de politika faizinin sabit terimli ve trend değişkenli modelde deterministik değişkenlerin etkisi ile Fourier fonksiyonlarının yukarı yönlü trendine devam edeceğini göstermektedir. Sabit terimli ve sabit terim-trend değişkenli modellerdeki Fourier fonksiyonlar karşılaştırıldığında sabit terimli modellerdeki Fourier fonksiyonları dalga boylarının daha uzun ve yatay bir bant içerisinde hareket ettiği görülmektedir. Sabit terimli ve trend değişkenli modelde dalga boylarının kısalması para ikamesi ve politika faizini belirleyen dışsal faktörlerin etkisinin daha fazla olduğunu işaret etmektedir.

Çalışmada değişkenler arasındaki ilişkinin varlığının ve yönünün tespit edilebilmesi amacıyla hem geleneksel hem de Fourier nedensellik testlerine başvurulmaktadır. Bu kapsamda ilk olarak bir değişkenin, başka bir değişken üzerindeki etkisinin tahmin edilmesine olanak sağlayan ve literatüre ilk nedensellik testi olarak geçen Granger (1969) nedensellik testine göre, iki değişken arasında dört yönlü nedensellik ilişkisi bulunabilmektedir. Söz konusu bu değişkenlerin $X$ ve $Y$ olduklarının kabul edilmesi durumunda nedensellik ilişkisi; X'den Y'ye tek yönlü, Y'den X'e tek yönlü hem X'den Y'ye 
Bayat, T. \& Ş. Taş (2021), “Türkiye'de Para İkamesine Karşı Politika Faizi Etkin

Olarak Kullanıliyor Mu? Fourier Alandan Kantllar”, Sosyoekonomi, 29(50), 503-520.

hem de Y'den X'e iki yönlü ve son olarak X ve Y arasında ilişkinin olmaması durumu olarak dört farklı şekilde gerçekleşmektedir.

$\mathrm{Bu}$ kapsamda yukarıda yer alan tanımlar iki değişkenli modeller kullanılarak gösterilecek olursa, $X_{t}, \quad Y^{\prime}$ nin sıfir ortalamalı iki durağan zaman serisi olduğu varsayılmaktadır. Bu durumda basit bir nedensel model aşağıdaki gibidir:

$$
\begin{aligned}
& X_{t}=\sum_{j=1}^{m} a_{j} X_{t-j}+\sum_{j=1}^{m} b_{j} Y_{t-j}+\varepsilon_{t}, \\
& Y_{t}=\sum_{j=1}^{m} c_{j} X_{t-j}+\sum_{j=1}^{m} d_{j} Y_{t-j}+\omega_{t},
\end{aligned}
$$

Modele göre; $\varepsilon_{t}$ ve $\omega_{t}$, korelasyonun bulunmadığı beyaz gürültü (white-noise) hata terimleridir. bj'nin sıfır olmaması durumunda $Y_{t}^{\prime}$ nin $X_{t}^{\prime} y e$ neden olmaktadır. Benzer şekilde, cj sıfır değilse $X_{t} Y_{t}{ }^{\prime} y e$ neden olmaktadır. Söz konusu varsayımların her ikisi de meydana gelirse, bu durumda $X_{t}$ ve $Y_{t}$ arasında bir geri bildirim ilişkisi yani çift yönlü nedensellik olduğu kabul edilir (Granger, 1969: 431).

Toda and Yamomoto (1995), VAR (k) modelinin tahminine dayanan Granger nedensellik testinden farklı olarak rastgele bir sırayla bütünleşmiş veya eş-bütünleşmiş olsa bile, seviyelerde formüle edilmiş VAR modellerinin nasıl tahmin edebileceğinin ve parametre matrislerindeki genel kısıtlamalarının nasıl test edebileceğini göstermektedir. Standart asimptotik teori geçerli olduğundan (sürecin bütünleşme sırası modelin gerçek gecikme uzunluğunu aşmadığı sürece) bütünleşik veya eş-bütünleşik bir VAR'a olağan bir gecikme seçim prosedürü uygulanabilmektedir. Gecikme uzunluğu (k) belirlendikten sonra (d) ile ifade edilen maksimum bütünleşme derecesine karar verilmektedir. Söz konusu süreçlerin ardından Toda and Yamomoto (1995) testi VAR (p+d) modelinin tahminini önermektedir. Modeldeki son gecikmeli vektörlerin katsayı matrisleri göz ardı edilerek ve standart asimptotik teori kullanarak ilk k katsayısı matrisleri üzerindeki doğrusal veya doğrusal olmayan kısıtlamaları test edebilir ve böylece serilerin durağan olmasına gerek duyulmadan serilerin daha fazla bilgi içermesi sağlanabilir.

Enders \& Jones (2016) ve Nazlığlu, vd., (2016)'nin geliştirdikleri testler ise Fourier nedensellik test istatistikleridir ve çalışmada her ikisi de tek frekans ve kümülatif frekans olarak dikkate alınmıştır. Ancak iki test arasında Enders \& Jones (2016)'un Granger (1969) nedensellik test prosedürlerini baz alması, Nazlığlu, vd., (2016)'nin ise Toda \& Yamamoto (1995) test prosedürünü uygulamaları yönünden farklılık bulunmaktadır.

Enders \& Jones (2016)'a göre herhangi bir değişkendeki kırılma, sistemin diğer değişkenlerinde de kendini göstereceğinden, kırılmanın orijinal kaynağını açıklamak zor olacaktır. Bu kapsamda VAR modelindeki kırılmalar uygun şekilde kontrol edilmedikçe, tahmin edilen model yanlış tanımlanacak, böylece tüm dürtü yanıtları ve varyans ayrıştırmaları sorunlu olacaktır. Bu nedenle söz konusu kırılma sayısını, kırılma şekillerini ve tarihlerini doğru bir şekilde tahmin etme problemini basitleştirmek için Fourier yaklaşımının kullanılması önerilmektedir. Enders \& Jones (2016), Gallant'1 (1981) 
izleyerek, zaman serilerinin deterministik parçasını temsil etmek üzere (9) no’lu denklemdeki Fourier serisi yaklaşımını uygulamaktadır.

$$
d_{i t}=a_{i 0}+\sum_{k=1}^{n} a_{i k} \sin \left(\frac{2 \pi k t}{T}\right)+\sum_{k=1}^{n} b_{i k} \cos \left(\frac{2 \pi k t}{T}\right)
$$

dit, zamanın potansiyel olarak yumuşak geçişli fonksiyonunu göstermektedir. $k$, Fourier fonksiyonunun frekans sayısını; $t$, eğilim (trend) terimini ve $T$ ise örneklem büyüklüğünü temsil etmektedir. $\pi, 3.1416$ 'ya eşittir (Enders \& Jones, 2016: 5).

Nazlıoğlu vd. (2016) Toda-Yamamoto testini, Fourier kademeli kırılma yaklaşımını uyarlayarak yapısal kırılmaları dikkate almak amacıyla $(\alpha)$ kesişme tarihlerinin zaman içinde sabit olduğu varsayımını genişleterek VAR modelini aşağıdaki gibi modifiye etmektedirler.

$$
y_{t}=\alpha(t)+\beta_{1} y_{t-1}+\cdots+\beta_{p+d}+y_{t-(p+d)}+\epsilon_{t}
$$

$\alpha(t)$ zamanı $y_{t}$ ise herhangi bir yapısal kırılmayı göstermektedir. Nazlıŏlu, vd., (2016) Yapısal kırılmaları tarihi, sayısı ve şekli bilinmeyen kademeli bir süreç olarak yakalamak için Fourier açılımı aşağıdaki gibi tanımlamaktadır:

$$
\alpha(t)=\alpha_{0}+\sum_{k=1}^{n} \gamma_{1 k} \sin \left(\frac{2 \pi k t}{T}\right)+\sum_{k=1}^{n} \gamma_{2 k} \cos \left(\frac{2 \pi k t}{T}\right)
$$

Burada $\mathrm{n}$, frekansların sayısıdır, $\gamma_{1 k}$ ve $\gamma_{2 k}$ sırasıyla frekansın genişliğini ve yer değiştirmesini ölçer. Denklem 10 ve 11 birleştirildiğinde 12 no'lu denklem elde edilir.

$$
\alpha(t)=\alpha_{0}+\gamma_{1} \sin \left(\frac{2 \pi k t}{T}\right)+\gamma_{2} \cos \left(\frac{2 \pi k t}{T}\right)
$$

Denklemdeki k yakınlaşma frekansını temsil etmektedir. 12 no'lu denklem 10 no'lu denklemin içine yerleştirildiğinde ise aşağıda yer alan 4 nolu denklem elde edilmektedir.

$$
y_{t}=\alpha_{0}+\gamma_{1} \sin \left(\frac{2 \pi k t}{T}\right)+\gamma_{2} \cos \left(\frac{2 \pi k t}{T}\right)+\beta_{1} y_{t-1}+\cdots+\beta_{p+d}+y_{t-(p+d)}+\epsilon_{t}
$$

Toda-Yamamoto yaklaşımında sıfır hipotezi Granger nedensellik yoktur şeklinde kurulmakta ve sıfır hipotezinin reddedilmesi durumu Granger nedenselliğin olmadığını kanıtlamaktadır. Hem Toda-Yamamoto, hem de Fourier Toda-Yamamoto testlerinin sifir hipotezini reddetmesi halinde ise elde edilen sonuçlar daha sağlam bir yapı arz etmektedir (Nazlıoğlu vd., 2016: 14).

Tablo 3'te yer alan nedensellik test sonuçlarına göre kullanılan bütün nedensellik testlerinde para ikamesinden faizlere doğru nedensellik ilişkisi olduğu görülmektedir. Yani para ikamesinin faizlerin nedenseli olmadığını ifade eden $\mathrm{H}_{0}$ hipotezi Enders ve Jones (2016) nedensellik testi dişında $\% 1$ anlamlılık düzeyinde reddedilmekte ve para ikamesinden faizlere doğru nedensellik ilişkisi olduğu kabul edilmektedir. Fakat faizlerden para ikamesine doğru nedensellik ilişkisi olduğuna dair kanıt bulunamamıştır. Bu da 
çalışmamızın ana sorusu olan Türkiye'de faizlerin para ikamesini etkileme gücünün olup olmadığı konusuna açıklık kazandırmıştır. Bu bağlamda tüm sonuçlar bir arada değerlendirildiğinde, Türkiye'de para ikamesi düzeyinin faiz oranları üzerinde etkiye sahip olduğu, faiz oranlarındaki değişimin ise para ikamesi üzerinde bir değişikliğe neden olmadığı yani para ikamesinin başka belirleyicileri olduğu görülmektedir.

Tablo: 3

Nedensellik Test Sonuçları

\begin{tabular}{|c|c|c|c|c|c|c|}
\hline \multicolumn{7}{|c|}{ Ho: CS, WACF'in Granger Nedenseli Değildir } \\
\hline & Wald & Asymp. p değeri & Boots. p değeri & $\mathrm{K}$ & $\mathrm{p}$ & $\mathrm{d}_{\max }$ \\
\hline Standart GC (Granger, 1969) & 21.534 & $0.00 * * *$ & $0.00 * * *$ & - & 3 & - \\
\hline TY ve Bootstrap TY (Toda ve Yamomoto, 1995) & 20.613 & $0.00 * * *$ & $0.00 * * *$ & - & 2 & 1 \\
\hline Fourier Standart GC Tek Frekanslı (Enders ve Jones, 2016) & 7.032 & $0.00^{* * * *}$ & $0.01 * *$ & 3 & 1 & - \\
\hline Fourier TY Tek Frekanslı (Nazliogu vd., 2016) & 20.042 & $0.00^{* * *}$ & $0.00 * * *$ & 3 & 2 & 1 \\
\hline Fourier Standart GC Kümülatif Frekanslı (Enders ve Jones, 2016) & 12.601 & $0.00^{* * * *}$ & $0.00 * * *$ & 3 & 1 & - \\
\hline Fourier TY Kümülatif Frekanslı (Nazlioglu vd., 2016) & 21.529 & $0.00^{* * * *}$ & $0.00 * * *$ & 3 & 2 & 1 \\
\hline \multicolumn{7}{|c|}{ Ho: WACF, CS'in Granger Nedenseli Değildir } \\
\hline & Wald & Asymp. p değeri & Boots. p değeri & $\mathrm{K}$ & $\mathrm{p}$ & $\mathrm{d}_{\max }$ \\
\hline Standart GC (Granger, 1969) & 0.987 & 0.804 & 0.815 & - & 3 & - \\
\hline TY ve Bootstrap TY (Toda ve Yamomoto, 1995) & 0.697 & 0.706 & 0.699 & - & 2 & 1 \\
\hline Fourier Standart GC Tek Frekanslı (Enders ve Jones, 2015) & 0.092 & 0.762 & 0.752 & 3 & 1 & - \\
\hline Fourier TY Tek Frekanslı (Nazlioglu vd., 2016) & 0.201 & 0.904 & 0.908 & 3 & 2 & 1 \\
\hline Fourier Standart GC Kümülatif Frekanslı (Enders ve Jones, 2015) & 0.857 & 0.355 & 0.36 & 3 & 1 & - \\
\hline Fourier TY Kümülatif Frekanslı (Nazlioglu vd., 2016) & 0.213 & 0.899 & 0.898 & 3 & 2 & 1 \\
\hline
\end{tabular}

Notlar: $* * *, * * v e *$ değerleri sirasiyla $\% 1 . \% 5$ ve \%10 anlam seviyelerinde alternatif hipotezin kabul edildiğini göstermektedir. Bootstrap saylsı 1000'dir. $k$ optimal frequency, $p$ optimal gecikme uzunluğu, GC; Granger Causality (Granger Nedensellik), TY; Toda-Yamamoto Causality (Toda-Yamamoto Nedensellik) ifade etmektedir. Optimal gecikme uzunluğunun seçilmesinde Akaike Bilgi Kriteri kullanılmaktadır.

Elde ettiğimiz sonuçları destekler nitelikte olan literatürde yer alan çalışmalara bakıldığında; Bacha vd. (2009) reel faiz oranının sistemik risk belirleyicilerini analiz etmek için finansal dolarizasyon (para ikamesi) literatürünün kapsamını genişletmek amacıyla hazırladıkları çalışmalarında 1996-2004 döneminde 66 ülkeden oluşan bir panel oluşturmuşlar ve ampirik analizlerinin neticesinde mevduat dolarizasyonun reel faiz oranını olumsuz etkilediği yani artırdığı sonucuna ulaşmışlardır. Darıcı (2004) çalışmasında bir ülkede para ikamesinin yüksek olması durumunun para politikasının etkin bir şekilde uygulanmasına engel olacağını ve merkez bankalarının politikalarının sonuçlarının istenildiği gibi olmayacağının altını çizmektedir. Ekonomide yerli para biriminin yanında yabancı para biriminin de yer alması, merkez bankasının piyasadaki yabancı para arzı üzerinde etkiye sahip olmaması nedeni ile faiz oranın araç olarak kullanıldığı politikaların uygulanmasını zorlaştıracak ve faiz oranlarında değişiklik meydana gelecektir. Bu kapsamda para ikamesi düzeyinin faiz oranları üzerinde etkiye sahip olduğu görülmektedir. Çalışmada ayrıca Türkiye'de para ikamesi sürecinde Türk lirasındaki değer kaybının ve fiyatlar genel düzeyindeki artışların önemli bir belirleyici olduğu belirtilmektedir.

Fretias (2003) para ikamesi histerisini Bolivya, Türkiye ve Endonezya için incelediği çalışmasında değişkenler olarak döviz tevdiat hesapları, yurtiçi bono nominal faiz oranları, döviz mevduatına uygulanan faiz oranları, döviz kurundaki değişmelerin beklenen değeri, ulusal paranın yurtiçi getirisi kullanmıştır. En Küçük Kareler Yöntemi kullanılarak yapılan analizlerin neticesinde Türkiye ekonomisinde faiz oranlarının para ikamesi üzerinde önemli 
Bayat, T. \& Ş. Taş (2021), "Türkiye'de Para İkamesine Karşı Politika Faizi Etkin

Olarak Kullanılıyor Mu? Fourier Alandan Kanıtlar”, Sosyoekonomi, 29(50), 503-520.

bir role sahip olmadığı, enflasyonun ve döviz kurlarının para ikamesi üzerinde etkili olduğu sonucuna ulaşılmıştır. Olayungbo ve Ajuwon (2015) yapısal vektör otoregresyonunun (SVAR) bir tahmin tekniğiyle birlikte, zamansal para-fayda modelini benimsedikleri çalışmalarının sonucunda istikrarlı ve düşük faiz oranlarına rağmen para ikamesinin artışta olduğu ve bu nedenle düşük faiz oranlarının para ikamesini caydırıcı bir etkisinin olmadığının altı çizilmektedir. Bununla beraber para ikamesinden enflasyona doğru tek yönlü bir nedensellik ilişkisi tespit edilmektedir. Bu bağlamda söz konusu çalışmalar bir arada değerlendirildiğinde Türkiye'de para ikamesinin faiz oranları dışında başka belirleyicilerinin olduğu (döviz kurları ve enflasyon gibi) anlaşılmakta, bununla beraber para ikamesinin faizler üzerinde etkiye sahip olduğu görülmektedir.

\section{Sonuç ve Politika Önerileri}

Türkiye'de 24 Ocak 1980 kararlarının ardından kambiyo rejiminde yapılan değişiklikler ile yabancı para birimleri ile ilgili kısıtlamaların ortadan kaldırılması ile birlikte yabancı para birimleri işlem ve saklama amaçlı gibi nedenler ile kullanılmaya başlanmıştır. Yaşanan bu sürecin sonucunda para ikamesi yani dolarizasyon olgusu ülke ekonomisinde yer bulmaya başlamıştır. Türkiye'de enflasyon ve para ikamesi arasında ilişki olduğu (Bahmani-Oskooee \& Domac, 2003) su götürmez bir gerçektir. Ayrıca döviz kurunda yaşanan dalgalanma sonucu paranın değer kaybının da enflasyonla beraber para ikamesine neden olan faktörlerden olduğu görülmektedir (Elifoğlu \& Taşseven, 2015).

$\mathrm{Bu}$ çalışmada ise söz konusu değişkenlere alternatif olarak para ikamesi sürecinde faiz oranlarının etkinliği araştırılmaktadır. Bu kapsamda Türkiye' de Ocak 2011-Kasım 2020 dönemi için faiz değişkeni olarak Türkiye Cumhuriyet Merkez Bankası ağırlıklı ortalama fonlama maliyeti (weighted average cost of the CBRT, WACF), para ikamesi göstergesi olarak ise döviz tevdiat hesaplarının M2 para arzına oranı (CS) baz alınmaktadır. Değişkenler arasındaki ilişkiyi tespit etmek amacıyla Granger (1969), Toda ve Yamomoto (1995), Enders ve Jones (2016), Nazlioglu, vd. (2016) tarafından geliştirilen geleneksel ve Fourier nedensellik testleri kullanılmıştır. Ampirik analiz sonuçlarına göre para ikamesinden faizlere doğru nedensellik ilişkisi bulunmakta, faizlerden para ikamesine doğru ise herhangi bir nedensellik ilişkisi bulunmamaktadır. Elde edilen bulgular Freitas (2003), Darıc1 (2004), Bacha vd. (2009) ve Olayungbo ve Ajuwon (2015)'un çalışmaları ile de desteklenmektedir. Nedensellik sonuçlarına bir bütün olarak bakıldığında ilk olarak Türkiye'de para ikamesinin faizler üzerinde etkiye sahip olduğu görülmektedir. Bu bağlamda para arzı içinde yabanc1 para miktarının artması, merkez bankasının para arzı üzerindeki kontrolünü zayıflatır ve para ikamesinin faiz oranlarını etkilemesi, faiz oranları üzerinde bir baskı yaratır.

Yine para ikamesinin yüksek oluşu döviz kurlarının artmasına sebep olacağından böyle bir ortamda döviz kurlarını aşağıya çekme amaçlı olarak faiz oranlarında artışa gidilmesi muhtemel olacaktır. Dolayısıyla para ikamesi düzeyi faizler üzerinde etkili olmaktadır. İkinci olarak faizlerdeki değişikliğin para ikamesi üzerinde etkili olmaması durumu ise Türkiye'de para ikamesinin döviz kurlarında dalgalanma ve dolayısıyla Türk lirasındaki değer kaybı, enflasyon gibi faizler dışında başka belirleyicilerinin olduğuna işaret 
etmektedir. Çalışmada ayrıca Kwiatowski vd. (1992) tarafından geliştirilen birim kök testi ve Becker vd. (2006) tarafından geliştirilen Fourier KPSS testi kullanılarak Türkiye'de para ikamesi histerisi ve faiz histerisinin varlığı araştırılmıştır elde edilen sonuçlar neticesinde para ikamesi histerisinin mevut olduğu ancak faiz histerisinin olmadığı görülmüştür.

Ekonomik birimler para ikamesine geçiş süreçlerinde para birimini değiştirmeleri nedeni ile sabit bir maliyetle karşılaşmakta ve bu maliyet bir enflasyon band oluşturmaktadır. Bu durumun sonucunda ise enflasyondaki geçici değişiklikler, ekonominin para ikamesi derecesinde kalıcı etkilere ve dolayısıyla para ikamesi histerisinin oluşmasına sebep olacaktır (Guidotti \& Rodriguez, 1992). Ayrıca yerli ve yabancı para birimlerinin ödeme aracı olarak mükemmel ikame olmaları durumunda, döviz talebi istikrarın sağlamasının ardından bile azalmayacaktır (Freitas, 2003). Son olarak, para ikamesi histerisinin yalnızca ekonomiye yönelik güven eksikliğinden oluşmadığı, özellikle bazı finans piyasalarında portföy çeşitlendirmesinin sınırlı olmasından dolayı dövizin alternatif bir araç olarak hem nakit hem de mevduat biçiminde kullanılmasından ortaya çıktığ görülmektedir (Havrylyshyn \& Beddies, 2003).

Çalışmadan elde edilen sonuçlara göre; Türkiye'de faizlerin para ikamesi sürecinde etkili olmadığ 1 , bu kapsamda para politikasının etkinliğinin azalmasına sebep olan, ekonomik ve sosyal anlamda sıkıntılar doğurabilen para ikamesi sürecinin önüne geçilebilmesi adına Türkiye ekonomisinde para ikamesini etkileyen faktörler belirlenerek bu doğrultuda düzenlemeler yapmak önem arz etmektedir. Bu bağlamda özellikle döviz kurlarının istikrarlı bir yapıya kavuşturulmasının ve enflasyon oranının düşürülmesinin gerektiği görülmektedir. Bununla birlikte para ikamesinin faiz oranlarını etkilemesi ve para ikamesi histerisinin varlığı nedeniyle de politika yapıcıların konuyla ilgili düzenlemeler yapması gerektirmektedir. Bunun içinde uygun para politikası ve maliye politikası bileşimleri kullanılarak ülkedeki makroekonomik istikrarın sağlanması ekonomik birimlerin olumlu beklentilere sahip olmalarına yol açarak para ikamesini azalmasına katkıda bulunabilecektir.

\section{Kaynaklar}

Adom, A.D. et al. (2009), “Currency Substitution in Selected African Countries”, Journal of Economic Studies, 36(November), 616-640.

Aigheyisi, O.S. (2015), "Currency Substitution, Inflation and Economic Growth in Nigeria: A Simultaneous Equations Analysis", The Empirical Econometrics and Quantitative Economics Letters, 4(1), 33-44.

Akçay, O.C. et al. (1997), "Currency Substitution and Exchange Rate Instability: The Turkish Case”, European Economic Review, 41(3-5), 827-835.

Aziakpono, M. \& S. Babatope-Obasa (2004), "Financial Liberalization, Currency Substitution and Savings in Nigeria: Evidence From Cointegration and Error Correction Modeling”, South African Journal of Economic and Management Sciences, 7(2), 316-340.

Bacha, E.L. et al. (2009), "A Panel-Data Analysis of Interest Rates and Dollarization in Brazil”, Revista Brasileira de Economia, 63(4), 341-360. 
Bahmani-Oskooee, M. \& I. Domac (2003), "On The Link Between Dollarisation and Inflation: Evidence from Turkey”, Comparative Economic Studies, 45(3), 306-328.

Balaylar, N.A. \& A.A. Duygulu (2004), “Türkiye'de Para İkamesi Olgusu ve Para Talebinin İstikrarı", DEÜ IIIBF Dergisi, 19(2), 33-55.

Becker, R. et al. (2006), "A Stationarity Test in the Presence of an Unknown Number of Smooth Breaks", Journal of Time Series Analysis, 27(3), 381-409.

Bernholz, P. (1989), “Currency Competition, Inflation, Gresham's Law and Exchange Rate”, Journal of Institutional and Theoretical Economics (JITE)/Zeitschrift für die gesamte Staatswissenschaft, 45(3), 465-488.

Calvo, G.A. \& C. Vegh (1992), “Currency Substitution in Developing Countries: an Introduction”, IMF Working Paper No. 92/40.

Canto, V.A. \& G. Nickelsburg (1987), Currency Substitution, Springer, Dordrecht.

Civcir, I. (2005), "Dollarization and Its 1-Long-run Determinants in Turkey", Research in Middle East Economics, Emerald Group Publishing Limited, (6), 201-232.

Clements, B. \& G. Schwartz (1993), "Currency Substitution: The Recent Experience of Bolivia", World Development, Elsevier, 21(11), 1883-1893.

Cuddington, J. (1989), "Commodity Export Booms in Developing Countries", The World Bank Research Observer, 4(2), 143-165.

Darıcı, B. (2004), "Para İkamesi Olgusu ve Türkiye Ekonomisi Üzerine Etkileri”, Yüksek Lisans Tezi, Balıkesir Üniversitesi Sosyal Bilimler Enstitüsü, Balıkesir, Türkiye.

Doguwa, S.I. (2014), "Currency Substitution: Evidence from Nigeria”, CBN Journal of Applied Statistics, 5(2), 1-23.

Domac, I. \& M. Bahmani-Oskooee (2002), "Between Dollarization and Inflation: Evidence from Turkey”, Discussion Paper 0207, Research and Monetary Policy Department, Central Bank of the Republic of Turkey.

Drazen, A. \& E. Helpman (1990), "Inflationary Consequences of Anticipated Macroeconomic Policies", The Review of Economic Studies, 57(1), 147-164.

Edwards, S. \& M.S. Khan (1985), "Interest Rate Determination in Developing Countries: A Conceptual Framework", NBER Working Papers 1531, National Bureau of Economic Research, 377-403.

Elifoğlu, H. \& Ö. Taşseven (2015), "Macroeconomic Determinants of Currency Substitution in Turkey”, Global Business Research Symposium May 27-29, İstanbul: Beykent.

Enders, W. \& P. Jones (2016), "Grain Prices, Oil Prices, and Multiple Smooth Breaks in a VAR", Studies in Nonlinear Dynamics \& Econometrics, 20(4), 399-419.

Feige, E.L. (2003), "Dynamics of Currency Substitution, Asset Substitution and De Facto Dollarisation and Euroisation in Transition Countries", Comparative Economic Studies, 45(3), 358-383.

Fendoğlu, E. \& E.C. Gökçe (2019), “Türkiye'nin Turizm Geliri Serisinin Durağanlığı: Fourier KPSS Durağanlık Testi”, Journal of Econometrics and Statistics, (31), 17-28.

Fielding, D. \& A. Shortland (2012), “The Dynamics of Terror During the Peruvian Civil War", Journal of Peace Research, 49(6), 847-862. 
Freitas, M.L.D. (2003), "Revisiting Dollarisation Hysteresis: Evidence from Bolivia, Turkey and Indonésia", NIPE Working Papers 12/2003, NIPE, Universidade do Minho.

Ghaderi, S. (2017), "The Hysteresis Effect of Currency Substitution in Iran: Divisia Index Approach", Iranian Journal of Economic Research, 22(72), 187-212.

Ghobaee-Arani, Z. et al. (2018), "Welfare Effects of Currency Substitution in Iran (1959-2013)", Monetary \& Financial Economics, 25(15), 251-274.

Giovanni, A. \& B. Turtelboom (1992), “Currency Substitution”, NBER Working Paper, No: 4232.

Girton, L. \& D. Roper (1981), “Theory and Implications of Currency Substitution”, Journal of Money, Credit and Banking, 13(1), 12-30.

Granger, C.W. (1969), "Investigating Causal Relations by Econometric Models and Cross-Spectral Methods", Econometrica, 37(3), 424-438.

Guidotti, P.E. \& C.A. Rodriguez (1992), "Dollarization in Latin America: Gresham's law in reverse?”, International Monetary Fund, IMF Economic Review, 39(3), 518-544.

Havrylyshyn, O. \& C.H. Beddies (2003), "Dollarisation in the Former Soviet Union: From Hysteria to Hysteresis", Comparative Economic Studies, 45(3), 329-357.

İmrohoroğlu, S. (1994), "GMM Estimates of Currency Substitution Between the Canadian Dollar and the US Dollar", Journal of Money, Credit and Banking, 26(4), 792-807.

Kumamoto, H. (2014), "Recent Experiences with Currency Substitution”, International Journal of Financial Research, 5(4), 1-12.

Kwiatkowski, D. et al. (1992), "Testing the Null Hypothesis of Stationarity Against the Alternative of a Unit Root", Journal of Econometrics, 54(1-3), 159-178.

Manjani, O. (2015), "Estimating the Determinants of Financial Euroization in Albania", Graduate Institute of International and Development Studies Working Paper, No. 07/2015.

McKinnon, R.I. (1982), "Currency Substitution and Instability in the World Dollar Standard", The American Economic Review, 72(3), 320-333.

Nazlioglu, S. et al. (2016), "Oil Prices and Real Estate Investment Trusts (REITs): Gradual-Shift Causality and Volatility Transmission Analysis", Energy Economics, 60, 168-175.

Olayungbo, D.O. \& K.T. Ajuwon (2015), "Dollarization, Inflation and Interest Rate in Nigeria", Journal of applied Statistics, 6(1), 241-261.

Oomes, N. (2003), "Network Externalities and Dollarization Hysteresis: The Case of Russia", IMF Working Paper, No. 03/96.

Ortiz, G. (1983), "Currency Substitution in Mexico: The Dollarization Problem”, Journal of Money, Credit and Banking, 15(2), 174-185.

Özbilgin, H.M. (2012), "Currency Substitution, Inflation, and Welfare”, Journal of Development Economics, 99(2), 358-369.

Pepić, M. et al. (2015), "Determinants of Currency Substitution in Southeast European Countries", Economic Themes, 53(2), 162-184.

Samreth, S. (2011), "An Empirical Study on the Hysteresis of Currency Substitution in Cambodia", Journal of Asian Economics, 22(6), 518-527.

Savastano, M.A. (1992), "The Pattern of Currency Substitution in Latin American: An Overview", Economic Analysis Review, 7(1), 29-72.

Selçuk, F. (1994), “Currency Substitution in Turkey”, Applied Economics, 26(5), 509-518. 
Shahin, W.N. \& F.G. Freiha (2005), "Hysteresis in currency substitution: the Middle East and North Africa", in: Money and Finance in the Middle East: Missed Oportunities or Future Prospects?, 165-181, Emerald Group Publishing Limited.

Sturzenegger, F. (1997), "Understanding the Welfare Implications of Currency Substitution", Journal of Economic Dynamics and Control, 21(2-3), 391-416.

Tkalec, M. (2013), "Determinants of Deposit Euroization in European Post-Transition Countries", Panoeconomicus, 60(1), 89-101.

Toda, H.Y. \& T. Yamamoto (1995), "Statistical Inference in Vector Autoregressions with Possibly Integrated Processes”, Journal of Econometrics, 66(1-2), 225-250.

Valev, N.T. (2010), “The Hysteresis of Currency Substitution: Currency Risk vs. Network Externalities, Journal of International Money and Finance, 29(2), 224-235.

Viseth, K.R. (2002), "Currency Substitution and Financial Sector Developments in Cambodia", International and Development Economics Working Papers, 1-4.

Westerlund, J. (2008), "Cointegration Tests of the Fisher Effect”, Journal of Applied Econometrics, 23(2), 193-233.

Yasuda, M. (2009), "Link Between Inflation, Exchange Rates and Currency Substitution in Russia", Conference of the Japan Association for Comparative Economic Studies (JACES) at Ritsumeikan University in Kusatsu, Japan, on (Vol. 24). 